\title{
Older People and ICT: Towards Understanding Real-Life Usability and Experiences Created in Everyday Interactions with Interactive Technologies
}

\author{
Sergio Sayago and Josep Blat \\ Interactive Technologies Group, Department of Information and Communication \\ Technologies (DTIC), Universitat Pompeu Fabra \\ C/Tànger, 122-140, E-08018 Barcelona, Spain (4th floor, room 55.408) \\ \{sergio.sayago, josep.blat\}@upf .edu
}

\begin{abstract}
This paper reports key findings on an ethnographical study of everyday interactions of older people with ICT. The research questions addressed are what easy or difficult to use means for older people in their daily interactions with ICT and what the relationship between usability and experiences created between older people and ICT is. 388 older people were observed and conversed with while using a wide array of ICT during 3 years. The results reveal that usability is related to independency. When ICT are easy to use, older people are independent users. Independency (dependency) can be identified by the number and type of questions, environmental noise disturbing interactions and required practice to master ICT. Independency leads to experiences that are emotionally fulfilling, supportive of exploration and reassuring. Dependency results in very sad experiences. These results suggest another way of seeing the interactions of older people with ICT, far from traditional individual age-related changes in functional abilities.
\end{abstract}

Keywords: Ethnography, older people, real interaction, usability, experience.

\section{Introduction}

"The old computing was about what computers could do; the new computing is about what users can do" [16, pp: 2]. As Information and Communication Technologies (ICT) are penetrating our lives and no longer used by professionals for productivity purposes, there is a need to widen the traditional research focus from usability in labs and performance of tasks to real-life usability and experiences created in the everyday interactions with ICT. Traditional methods for ensuring usability, such as the traditional laboratory-based usability testing, are largely meaningless in ordinary interactions [17]. Much more deeply than ever before, we are aware that interacting with technology creates experiences. And those concerned with the design, use and evaluation of interactive systems need to be able to understand and analyze people's felt experiences with technology [11]. It is also unclear how well existing usability techniques and measures will perform if the focus is on designing experiences that people enjoy or value while doing a wide range of activities in which productivity is not the primary concern [9]. 
Yet, there has been surprisingly very little research on real-life usability and user experience in human-computer interaction (HCI) with older people. Much research on usability with older people has been focused on adapting methods to older people's special needs $[1,6]$. The experiences created between older people and ICT seem not to have been addressed yet. A survey we did on leading HCI journals and conference proceedings show that no studies into user experience and older people have been published as yet ${ }^{1}$. Instead, the main concern is to compensate for individual age-related changes in functional abilities (sight, hearing, cognition and mobility). Nevertheless, older people are non-standard users in HCI research [4] and use ICT for non-productivity purposes [15]. Both facts provide a clear stimulus to explore usability "out of labs" and the felt experiences of older people with ICT.

This paper looks at everyday usability for older people and its relationship with their felt daily experiences with ICT. Older people are defined herein as adults ranging in age from 65 to 80 years old experiencing normal age-related changes in functional abilities. These changes do not have an impact on their ability to carry out ADL (Activities of Daily Living) and IADL (Instrumental Activities of Daily Living) on their own.

Regarding everyday usability, this paper aims to understand what easy or difficult to use mean for older people in their daily interactions with ICT. Within the traditional task performance model [9], easy and difficult to use are an indicator of productivity. The easier a system to use, the more tasks can be conducted in given period of time. Nevertheless, easy or difficult to use might have a completely different meaning for older people, since productivity is not their main concern when interacting with ICT.

With respect to user experience, this paper is intended to identify the relationship between usability and older people's experiences with ICT. As stated in [13], usability and user experiences are intertwined, being some combinations of usability and user experiences goals more compatible than others (e.g.; "it may not be possible or desirable to design a process control system that is both safe and fun" [pp: 20]). However, very little is known about the relationship (if any) between usability and user experience with older people.

Thus, the research questions addressed in this paper are:

1. What does easy or difficult to use mean for older people in their everyday interactions with ICT?

2. How does usability relate to the older people's felt daily experiences with ICT?

This paper has adopted an ethnographical approach in order to answer both questions. HCI has looked to ethnography in order to develop views of the interactions between people and technologies as they happen in naturally occurring settings. Gaining these insights is seen by academy, industry and corporate settings are an essential ingredient in design more useful and engaging technologies [2]. Ethnography allows designers

${ }^{1}$ Interacting with Computers; International Journal of Human-Computer Studies; Universal Access to the Information Society; ACM Transactions of Human-Computer Interaction; ACM Transactions of Accessible Computing; HCI - first issue - 2008; CHI ACM Proceedings, W4ALL, first conference - 2008. Keywords: experience, user experience, older people, older adults, elderly; ICT; interactive technologies; web; computers. 
and researchers to explore technologies "in the wild" [5] in a way that is difficult to do by using other methods [2].

This paper reports the key findings of an ethnographical study of everyday interactions of older people with ICT (mainly, web and computer technologies). The ethnographical data consisted of in-situ observations of and conversations with 388 older people while using a wide array of ICT on a daily basis. This ethnographical data was collected over 3 years. We analyzed this data by using open, axial and selective coding and the constant comparison technique of the Grounded Theory approach for qualitative analysis [8].

The results indicated that easy (difficult) to use means independency (dependency) for older people in their day-to-day interactions with ICT. Independency is the ability of older people to interact with interactive technologies on their own. This ability can be characterized by the number and type of questions, environmental noise disturbing interactions and required practice. The experiences created between older people and technologies that are easy to use can be defined as emotionally fulfilling, supportive of exploration and reassuring. The experiences with technologies with poor usability are emotionally unfulfilling, unsupportive of exploration and pessimistic.

\section{Description of the Ethnographical Study}

\subsection{Context}

The study was carried out in Àgora from 2005 to 2008. Àgora is a 20-years-old association within La Verneda-St.Marti adult centre (Barcelona, Spain). Àgora has a strong commitment to the integration of sectors ${ }^{2}$ that have been alienated from current society into the active fabric of it. Numerous courses in a wide array of subjects, ranging from languages to cooking, are offered on a daily basis. These courses are free of charge. Between 1000 and 1500 people (generally referred as 'participants') enroll on courses monthly.

Mastering ICT is regarded by Àgora and participants as an essential element for inclusion into contemporary society. Àgora offers a large number of courses in ICT, as well as daily Internet access and workshops. Most of these activities are aimed at older people, who are particularly disadvantaged. Older people decide what technologies they want to (learn to) use in courses and workshops. Their decision is grounded in the use they want to make of technologies in their daily lives (integration) rather than being imposed by pre-established syllabuses.

Participation is also a key pedagogical element. Àgora operates by using dialogic learning [7]. Agora is run by people who are deeply involved in activities. Agora blurs the traditional division between teachers and learners. A real scenario is that in which older people who started taking courses in ICT with little acquaintance with computers, now a command of them and become teachers for peers who are taking up ICT.

${ }^{2}$ About $50 \%$ of the current Catalan population has its origins from rural areas from elsewhere in Spain, the immigration taking place in the 1940-50s, immigrants having very low literacy levels, especially women. In the last 10 years a new (global) immigration wave has taken place with origins (mainly) in Morocco, South America and Romania, with an increase of about $10 \%$ of the existing population creating a new sector of potentially marginalized population, adding language problems to literacy issues. 


\subsection{Participants and Ethnographical Strategy}

We wished to develop a first-hand view of the interactions of older people with ICT as a prerequisite for understanding real-life usability and the experiences that are created with between older people and ICT. To this end, we found a classical ethnographical approach very valuable ${ }^{3}$. The observations and conversations took place initially during the courses. They provided us with extensive material of real use of ICT, very far from more artificial "training" settings, due to the strong participative approach discussed above.

Even though participants were not a representative sample of the older population in some ways ${ }^{4}$, they showed the real use that older people pioneers of ICT are making of these technologies. We think that this is likely to be the best approximation we can have to ethnography when introducing innovation. On the other hand, participants were very representative of ordinary people living in a developed country, as detailed next.

The participants were older Spanish people ranging in age from 65 to 80 years old. They hailed from Catalonia, the South and North of Spain. Participants lived in Barcelona and its outskirts. Participants experienced normal age-related changes in functional abilities (sight, hearing, cognition and mobility). However, these changes did not make them unable to carry out daily activities such as shopping, banking or cleaning on their own. They had different educational competencies and previous experience with ICT. 350 had low levels of education (i.e. degrees in primary school or basic literacy skills). These participants also had scant digital literacy skills, their experience being with calculators, cash registers and mobile phones. The rest of the participants (38) had higher educational levels (i.e. secondary school degrees or specific certificates related to their previous jobs). They were familiar with basic web and computer concepts, their experience being with specialized computer applications for their previous jobs (e.g. an internal e-mail system). Participants' main motives behind taking up ICT were not to lag behind in society, to be or remain closer to their children, grandchildren and friends, and to enjoy the opportunity of learning that they did not have in their childhood.

This profile was elaborated by conversing with the participants and other members of Àgora during the fieldwork. We also had access to the profile of the participants recorded and updated by Àgora.

\subsection{Data and Methods}

The data came from 388 participants. We observed and conversed with them 2 to 3 times per week. Each "contact time" lasted 2 hours. We used traditional paper and

\footnotetext{
${ }^{3}$ Ethnography consists of a long period (in anthropology, it has become relatively standard to think of a minimum of a year of fieldwork to gain sufficient insight) of immersion in people's everyday activities, combining observation with participation [3]. Other forms of ethnography (quick-and-dirty or lightweight, concurrent and evaluate ethnography) have been especially developed for HCI, to fit in with software engineering and user-centered design processes [12].

${ }^{4}$ Older people with a lack of experience with ICT constitute the majority of the older population living in Spain [10].
} 
pencil to record observations and participant's in-situ comments. Other methods such as video cameras and tape recorders were found to be very intrusive, in addition to being difficult to use in Âgora ${ }^{5}$. Part of this fieldwork took place in courses and workshops coordinated by us (212 participants: all courses except those in first row on Table 1, plus workshops). Another relevant part of our fieldwork was realized in courses and meetings where we attended as observers (176 participants: public meetings plus three courses in first row on Table 1). Table 1 provides specific details of the fieldwork.

Table 1. Details of our ethnographical study

\begin{tabular}{|c|c|c|c|}
\hline Course & Technologies & Participants & Duration \\
\hline $\begin{array}{l}\text { Gardens, Towns } \\
\text { in the world and } \\
\text { Internet }\end{array}$ & $\begin{array}{l}\text { Yahoo! mail, Hotmail, Google, MS } \\
\text { Word and PowerPoint, Websites } \\
\text { (transport, health, TV) }\end{array}$ & 72 & $\begin{array}{l}1 \text { course. } 6 \text { months. 2-hour } \\
\text { session every week (Gardens } \\
\text { and Towns in the World). The } \\
\text { internet course lasted } 1 \text { month. }\end{array}$ \\
\hline $\begin{array}{l}\text { Online commu- } \\
\text { nication }\end{array}$ & $\begin{array}{l}\text { Yahoo! mail, Hotmail, Chat, Blogs, } \\
\text { Wikis, Forums, Google, Yahoo! }\end{array}$ & 76 & $\begin{array}{l}\text { courses, which lasted } 3 \\
\text { months. 2-hour session every } \\
\text { week }\end{array}$ \\
\hline $\begin{array}{l}\text { Advanced as- } \\
\text { pects of the web } \\
\text { and computers }\end{array}$ & $\begin{array}{l}\text { MS Word, PowerPoint and Excel, Yahoo! } \\
\text { mail, Hotmail, Google, Yahoo!, Yahoo! } \\
\text { Flickr, Google Earth, Websites (flights } \\
\text { booking; routes; medical assistance) }\end{array}$ & 76 & $\begin{array}{l}4 \text { courses, which lasted } 3 \\
\text { months. 2-hour session every } \\
\text { week }\end{array}$ \\
\hline Online resources & $\begin{array}{l}\text { File management, Windows manage- } \\
\text { ment, Google, Yahoo!, Blogs, Yahoo! } \\
\text { Mail, Hotmail, websites (transport, TV, } \\
\text { health, traveling) }\end{array}$ & 18 & $\begin{array}{l}1 \text { course. It lasted } 6 \text { months. } \\
\text { 2-hour session every week. }\end{array}$ \\
\hline Workshops & Technologies & Partic & Duration \\
\hline $\begin{array}{l}\text { Workshop on } \\
\text { web }\end{array}$ & $\begin{array}{l}\text { Yahoo! mail, Hotmail, multimedia con- } \\
\text { tent edition, finding online information } \\
\text { (directories, search engines), websites } \\
\text { (transport, health, towns, news, TV) }\end{array}$ & 18 & $\begin{array}{l}3 \text { workshops. 2-hour session } \\
\text { every workshop }\end{array}$ \\
\hline $\begin{array}{l}\text { Workshop on } \\
\text { recent } \\
\text { technologies }\end{array}$ & $\begin{array}{l}\text { Blogs, Yahoo! Flickr, Yahoo! mail, } \\
\text { Hotmail, wikis, websites }\end{array}$ & 24 & 2 workshops. 2-hour session \\
\hline Public meetings & Technologies & Participants & Duration \\
\hline 7 meetings & $\begin{array}{l}\text { Technologies used in courses and work- } \\
\text { shops }\end{array}$ & 104 & Between 2 and 3 hours \\
\hline
\end{tabular}

All this data was analyzed by using open, axial and selective coding and the constant comparison technique of the Grounded Theory approach for qualitative analysis [8]. This analysis initially involved one of the authors reading the entire field notes to gain an overall sense of the data. All the data was then read again and open-coded to produce an initial code list. This was done until, in the opinion of the two authors of

${ }^{5}$ Participants were used to seeing people taking notes with traditional technologies, viz. paper and pencil. They took their notes using these technologies, so this s was a natural practice in courses, meeting and workshops. However, participants were not used to seeing people taking notes by using laptops. They were also not used to being recorded while going online or using computers. Furthermore, Âgora did not allow video cameras in computer classes on the grounds that these technologies made people that are alienated from society feel very uncomfortable, as well as providing an unnatural environment for (learning to) using ICT. 
this paper, analysis had reached theoretical saturation. Most of the codes were adapted from the language of the participants, rather than drawing solely on our review of literature. This reflected our attempt to tell the story of older people from their point of view, without theoretical preconceptions as to what will be found - which is the hallmark of ethnography. At the same time, axial coding was carried out to establish relationships between categories identified in open coding. From this basis, the data was then selectively coded in terms of core and subcategories categories identified with the initial and axial list of codes. The care and subcategories are listed below:

- Core category: Independency

Easy to use: few questions; questions aimed at "knowing more"; environmental noise does not hinder interactions; older people are either engrossed in their activities or waiting for doing other tasks patiently; no extra practice is required

- Supportive of exploration: willingness to explore in the unknown

- Reassuring: showing a desire to comfort those who are having difficulties

- Core category: Dependency

- Difficult to use: many questions; need of support to carry out a task; environmental noise hinders interaction (mainly, concentration); extra practice is required before trying to do more activities

- Emotionally unfulfilling: unhappy and unsatisfied with their abilities; older people feel useless despite all their efforts put in mastering ICT

- Unsupportive of exploration: reluctance towards exploring the technology due to their reliance on others

- Pessimistic: give up using technology; end up being unwilling to use them (although they might considering giving it a go)

These categories (and related codes) were also used to analyze 20 in-depth interviews and 12 group-based discussions ( 8 focus groups and 7 workshops - different from those displayed in Table 1) about e-mail systems, relevance of accessibility barriers and social relationships. There aspects were found to be of great importance in the everyday interactions of older people with ICT.

The findings, which follow, are drawn from a large collection of observations and conversations. They summarize what usability means for older people and the relationship between usability and experiences created between older people and ICT. These findings were chosen as being of most relevance and likely interest to both researchers and designers. We use vignettes and real scenarios in an attempt to (i) situate the findings into their context and (ii) both capture and preserve the opinions and comments expressed by the participants as much as possible.

\section{Key Findings}

\subsection{Dependency and Independency: A Matter of How Easy to Use ICT Are}

Scenario: Maria is 68 years old. She is selecting an area of a picture with MS Paint. She has downloaded the picture from the web. She wants to send this part of the 
picture, which has a funny message, to her friend, Carmen. She was independent when she downloaded the picture. She did not ask us any question about how to do that. She was engrossed in this activity. When she finished, she came to us to know more about alternative strategies for downloading pictures from the web. She has seen people downloading pictures by using several methods and she is curious about that. Nevertheless, Maria is a dependent user when it comes to select the area of the picture she wants to share with Carmen. She asked us 10 questions in 20 minutes. This is the amount of time she required to select a portion of a picture. She thanked us for having been attentive to her and patient, at the same time. She acknowledged that she might have given the impression that she was stupid or useless. However, she thinks that the problem is that selecting an area of a picture is really difficult. She also apologised for having made noise or disturbed the interactions of the rest of the participants. She drawn our attention to the fact that she, as the rest of the participants, were working silently when downloading pictures from the Web. However, the environmental noise increased considerably in the second task, working with MS Paint. She pointed out that older people do not make noise when something is easy to use or do. However, when they have difficulties, older people start suddenly to ask a large number of questions about how to do things, using a loud voice to make their inquiries heard.

Scenario: At 12.15, a group of 8 older people are creating a web page. This web page contains a table with 3 rows and 2 columns. The participants were having difficulties inserting the table into the web page. They asked for help to the instructor. A member of the staff in Àgora popped in the computer room and asked both the instructor and the participants not to make so much noise. "Are we disturbing you? We did not realise, sorry", a participant exclaimed. "Yes, you are making so much noise that my students in the next room can not concentrate on their activities. I do no know what you are doing, but 30 minutes ago it seemed as if there were no people here", the member of Àgora said. "30 minutes ago we were doing something very easy. Now, we are working on web pages and tables, and this is very difficult. We talk a lot among ourselves and ask him lots of questions...we make a lot of noise when something is difficult to use!" the same participant replied.

\subsection{Independency Leads to Emotionally Fulfilling, Supportive of Exploration and Reassuring Experiences}

Vignette "Manolo". Manolo is 72 years-old. He finds e-mailing very valuable for him and his wife. Staying in touch with people they love, especially their children and grandchildren, is of immense value for them. He thinks that there are no words to express how useful the e-mail is for him and his wife. Receiving an e-mail from their grandchildren is the best things of the day; he tends to say to their friends. Despite his initial difficulties using e-mail, Manolo is nowadays able to communicate by e-mail independently. He opens the web browser, logs into his e-mail account and starts emailing on his own. Being able to master this technology and use it autonosmously makes him proud of himself. He thinks that when an older person realizes that he or she is able to do what many people think he or she will never be able to do, that person is very proud of him or herself. They can reply to these people with three words: yes, I can. Manolo is well aware of the fact that many older people are not so lucky. They have difficulties in e-mailing and he gives them a hand. He feels that it is very 
frustrating to see that you have managed to do many things in your life and now you get stuck with a simple machine. For this reason, Manolo thinks he must help peers to master e-mail. When he interacts with e-mail systems, he has every confidence in his ability to master the technology, even it something wrong or unexpected happens. This feeling has encouraged him to learn more aspects of e-mailing. He has learned many things about e-mailing on his own. Manolo was taught the basis of e-mailing in Àgora, and he is indebted to his instructor. However, as he found e-mailing both very useful and easy, he started to explore it at home. Nowadays, he is capable of doing numerous things. He thinks that he outdoes some instructors and friends of mine. Emailing creates a range of experiences and emotions, all of them positive.

\subsection{Dependency Leads to Emotionally Unfulfilling, Unsupportive of Exploration and Pessimistic Experiences}

Vignette "Jordi". Jordi is 73-years-old. He is able to use some interactive technologies on his own, such as mobile phones and e-mail systems. However, he is not able to use other technologies, which he would like to use in daily life, on his own. These technologies are tools for editing web pages and working with images. He finds it very frustrating not to be able to master the technologies they want to use. This lack of ability creates feelings of great unhappiness and sometimes loss of hope, especially when he sees that he is uncapable of using technologies that other people use daily. Being able to use his mobile phone and e-mail systems is not enough. He wants to use more technologies, and not being able to do it makes him feel stupid and very old. New technologies are not for older people, this is what he hears in the street. He is against this view, but interacting with certain technologies brings back this stereotype. Xavier tries to explore technologies that he finds it difficult to use. He thinks he is stubborn, many older people are stubborn, he also thinks. He explores these technologies with very little confidence, however. He knows that he is going to fail, and this idea puts him off keeping on trying. Xavier has even given up some technologies, especially creating web pages. This fact created a very sad experience with ICT. Despite his willingness to use them, because he thinks that they are the future and relatives and friends urge him to use them, he thought that it was better for him to stick to the technologies that he could use on his own. There is no point in making my live more complex than it is, he says.

\section{Discussion}

The above sections give some examples of the insights we obtained by a long and detailed ethnographic study of the everyday interactions of older people with ICT. What does easy or difficult to use mean for older people in their everyday interactions with ICT and why? Usability is related to independency. When ICT are easy to use, older people are independent users. However, when they are difficult to use, older people are dependent users. Both dependency and independency can be identified by a number of factors that emerge naturally from real interactions: the number and type of questions, the amount of environmental noise disturbing interactions and the perceived need of practice. How does usability (independency or lack of it) related to 
older people's felt daily experiences with ICT? Technologies are that easy to use create experiences that we have categorised as: emotionally fulfilling, supportive of exploration and reassuring. Technologies that are difficult to use create opposite experiences: emotionally unfulfilling, unsupportive of exploration and pessimistic.

Some of themes resonate with those identified by previous research. The core categories of our analyses stress the relevance of independency in order to understand usability in context and its relationship with the experiences created between people and ICT. Research on ageing has claimed that independency is a key condition in later life [14]. Nevertheless, other themes that have emerged are very different to those that are commonly used in human-computer interaction research with older people. The bulk of research is focused on compensating for age-related changes in functional abilities. And most of this research has taken place in either labs or real contexts but under controlled scenarios. We have adopted a different approach, the emphasis being on interactions "in the wild", which is in line with the growing awareness in academy, industry, corporate settings and human-computer interaction to the need to understand how people interact and make use of technologies in the daily lives $[2,16,11]$. This approach has enabled us to identify certain aspects of the interactions of older people with interactive technologies that seem to have been untapped so far. Nevertheless, it is no longer considered sufficient to produce a computer system that is effective, flexible, learnable or satisfying to use, it must also enrich the users' experiences [11].

The vignettes and scenarios presented on Section 4 draw attention to the importance of usability in everyday interactions and experiences in older person's daily interactions with ICT. This raises the question of how we can measure usability in real-life interactions using the parameters suggested in this study and how we can design ICT that enrich older people's experiences with these technologies. Answering both questions warrant much more research; this study was a first step towards this goal. We have uncovered aspects for measuring real usability that need to be validated in follow-up studies. We expect to record participants' interactions in terms of the factors presented herein and identify how well these factors allow us to measure usability (e.g. how many questions mean "difficult" or "easy"?). With respect to experience, 'designing for the full range of human experience may well be the theme for the next generation of discourse about software design' (cited in [11], pp: 183). We hope this paper makes a small contribution to this larger debate. At the very least we hope we will provoke researchers and designers to look at the interactions of older people with information and communication technologies in a different light.

Acknowledgments. We are indebted to Àgora and our participants for allowing a stranger into an important part of their lives. We also want to thank Ernesto Arroyo for his comments on early versions of the manuscript.

\section{References}

1. Barrett, J., Kirk, S.: Running focus groups with elderly and disabled elderly participants. Applied Ergonomics 31, 621-629 (2000)

2. Blomberg, J., Burrell, M., Guest, G.: An ethnographic Approach to Design. In: Jacko, J.A., Sears, A. (eds.) The Human-Computer Interaction Handbook: Fundamentals, Evolving Technologies and Emerging Applications, pp. 964-987. Lawrence Erlbaum Associates, London (2003) 
3. Dewalt, K.M., Dewalt, B.R., Wayland, C.B.: Participant Observation. In: Bernard, H.R. (ed.) Handbook of Methods in Cultural Anthropology, pp. 259-301. AltaMira Press, California (2000)

4. Dickinson, A., Arnott, J.L., Prior, S.: Methods for human-computer interaction research with older people. Behaviour \& Information Technology 26(4), 343-352 (2007)

5. Dourish, P.: Implications for Design. In: CHI 2006, Montréal, Québec, Canada, pp. 541550 (2006)

6. Eisma, R., Dickinson, A., Goodman, J., Syme, A., Tiwari, L., Newell, A.F.: Early user involvement in the development of information technology-related products for older people. Universal Access in the Information Society 3, 131-140 (2004)

7. Flecha, R.: Sharing Words. Theory and practice of dialogic learning. Rosman \& Littlefield Publications, Maryland (2000)

8. Glaser, B.G., Strauss, A.L.: The discovery of grounded theory: strategies for qualitative research. Aldine Transaction, New Jersey (2006)

9. Karat, J.: Beyond Task Completion: Evaluation of Affective Components of Use. In: Jacko, J.A., Sears, A. (eds.) The Human-Computer Interaction Handbook: Fundamentals, Evolving Technologies and Emerging Applications, pp. 1152-1163. Lawrence Erlbaum Associates, London (2003)

10. Larra, R.M.d.: Los Mayores en la Sociedad de la Información: situación actual y retos de futuro, Fundación AUNA, Madrid (2004)

11. McCarthy, J., Wright, P.: Technology as experience. MIT Press, Cambridge (2004)

12. Randall, D., Harper, R., Rouncefield, M.: Fieldwork for Design. Theory and Practice. Springer, London (2007)

13. Rogers, Y., Sharp, H., Preece, J.: Interaction design: beyond human-computer interaction. John Wiley \& Sons, Chichester (2002)

14. Schaie, K.W., Boron, J.B., Willis, S.L.: Everyday Competence in Older Adults. In: Johnson, M.L. (ed.) The Cambridge Handbook of Age and Ageing, pp. 216-229. University Cambridge Press, Cambridge (2005)

15. Selwyn, N., Gorard, S., Furlong, J., Madden, L.: Older adults' use of information and communication technology in everyday life. Ageing \& Society 23, 561-582 (2003)

16. Shneiderman, B.: Leonardo's Laptop. Human needs and the new computing technologies. MIT Press, Cambridge (2002)

17. Thomas, P., Macredie, R.D.: Introduction to the New Usability. ACM Transactions on Computer-Human Interaction 9(2), 69-73 (2002) 